\title{
The role of microbiota in paleoecosystems for forming the molecular profile of coals
}

\author{
Oleksandr Balalaiev ${ }^{1, *}$ \\ ${ }^{1}$ Institute of Geotechnical Mechanics named by N. Poljakov of National Academy of Sciences of \\ Ukraine, 49005, Dnipro, Simferopolska, 2a, Ukraine
}

\begin{abstract}
Mass deposits of fossil coals can be formed in certain evolution periods of the Earth's biosphere, and they are the result of biogeocenosis functioning. A unique combination of ecological factors leads to the emergence of specific biomes with short trophic chains, an imbalance in the carbon cycle and desynchronization in the flows of substance and energy. The molecular structure of coal is a complex conglomerate of various stable organic compounds of primary and secondary metabolites of biogeocenosis reducers. The molecular profile includes numerous classes of low- and high-molecular organic substances that interact closely with each other. Multiple classes are not endless, the interaction is not chaotic, and their number and relationships are determined by paleoecologic patterns and coalification. Even a small fragment of the profile includes valuable information about the genesis of individual compounds and the biogeochemical situation when forming the coal bed. Microbiota impact does not end with a period of mortmass accumulation, which is never fully mineralized. In the coalification process, favorable environmental conditions may arise for the rebirth of the microorganisms' lives in coal beds.
\end{abstract}

\section{Introduction}

As known, coal has been formed from plant deposits, and it is a combustible fossil of biogenic origin. The modern concept of the molecular structure of coals is based on the theoretical model of Van Crevelen [1] and more than 133 different modifications for coals of various ranks, as well as their macerals [2]. The molecular models of most coals are interconnected carbon nuclei in the form of a graphite-like polyaromatic cluster with various peripheral functional groups.

Structural researches of coal are aimed at the prediction of physical and chemical parameters. The simulation consists in reconstructing a certain "averaged" molecular structure of the organic substance of coal according to its empirical formula or the results of the Nuclear Magnetic Resonance, Fourier-transform Infrared Spectroscopy, X-ray Diffractometry and Pyrolysis/Gas Chromatography/Mass Spectrometry experiments [3]. These models inevitably neglect by the interaction between the most structural fragments, since coal is a complex conglomerate of unequally distributed organic compounds.

*Corresponding author: gvrvg@meta.ua 
Therefore, it is methodologically more correct to consider not the molecular structure of coal, but the composition of its molecular profile.

It is postulated that the basis of the coal substance is made up of monomers and lignin and cellulose oligomers. It is believed that the pyrolysis of the main components of wood leads to energetically favorable rearrangements in the molecular structure when changing the thermodynamic conditions during the process of the coal bed plunge. In this case, only physical and chemical processes are taken into account, but not the reducing function of microbocenosis. Meanwhile, various types of microbiota under certain conditions effectively depolymerize cellulose and lignin even in the sedimentation period.

The purpose of the paper is to consider the ecological-evolutionary patterns of coal beds formation and to elucidate the genesis for the individual components of the molecular profile.

\section{Methodology}

The research rests on the theoretical principles of the structural-functional organization of modern biogeocenosis. It is taken into consideration that evolutionary metamorphoses of successive change of species may be reflected on the interconnections of the components in paleoecosystems of the sedimentation period. A logical ecological-evolutionary approach is applied to the genesis analysis of the molecular profile components in the coal substance.

The main experimental method for studying the molecular structure of Donbas coals for different degrees of coalification is Diffuse Reflection Infrared Fourier Transformation (DRIFT) of fine-dispersed coal powder. Additionally, the analysis of published images of High Resolution Transmission Electron Microscopy (HRTEM) and Atomic-force Microscopy (AFM) of the coal surface for other deposits is carried out.

\section{Results and Discussions}

The most reliable experimental method for studying the structure of any object is its direct observation. HRTEM and images are suitable for studying the molecular structure of amorphous solids. Despite the fact that HRTEM coals have a series of restrictions, dozens of scientific papers were devoted to this method, hundreds of digital images were obtained.

In the HRTEM image (Fig. 1a) of undisturbed bituminous coal [4], individual molecular structures are clearly seen. Visually, they are similar to aliphatic organic compounds with different numbers of carbon atoms, normal and branched structure, saturated and unsaturated links. AFM surface of intermolecular nanopores in gas coal [5], despite its lower resolution, also does not have a cellular structure (Fig. 1b).

However, most researchers interpret the following HRTEM texture as a result of interference of aromatic layers, oriented across the image plane. It is difficult to explain the presence of structural fragments of complex winding shape and branched structure not characteristic of the profile of graphite-like carbon structures by the generally accepted interpretation of the results. The strict orientation of all molecular structures exclusively in one plane is hardly inherent in natural objects. A detailed analysis of a large number of published images of different coals from various sources revealed only two hexagonal rings oriented in the image plane.

Meanwhile, the presence of many low-molecular compounds with a linear and branched skeleton is easily explained by the accumulation of primary and secondary metabolites of the biogenic decomposition of natural polymers. In order to understand this process, it is necessary to consider the principles in the functioning of biogeocenosis.

Any ecosystem is a continuous interaction of jointly functioning living organisms with the geological environment through the metabolism, energy, and information. The trophic 
structure of the ecosystem can be divided into two tiers: the upper autotrophic one - using the energy of the Sun for photosynthesis of complex organic compounds from simple inorganic substances and the lower heterotrophic tier - consuming the energy of decomposition of substances accumulated by phototrophs.

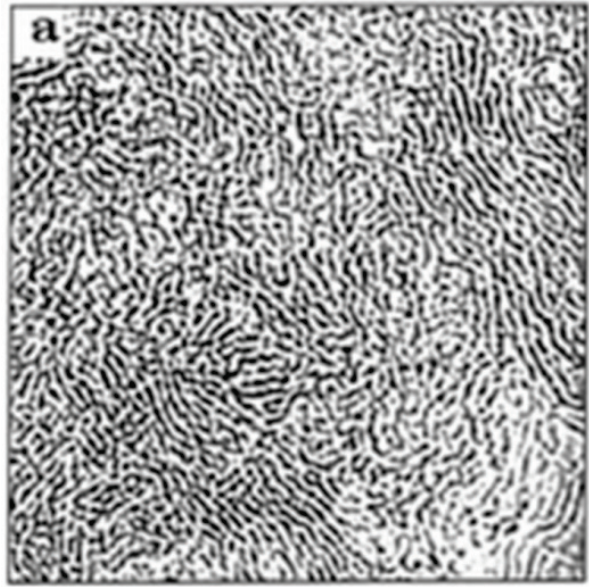

a

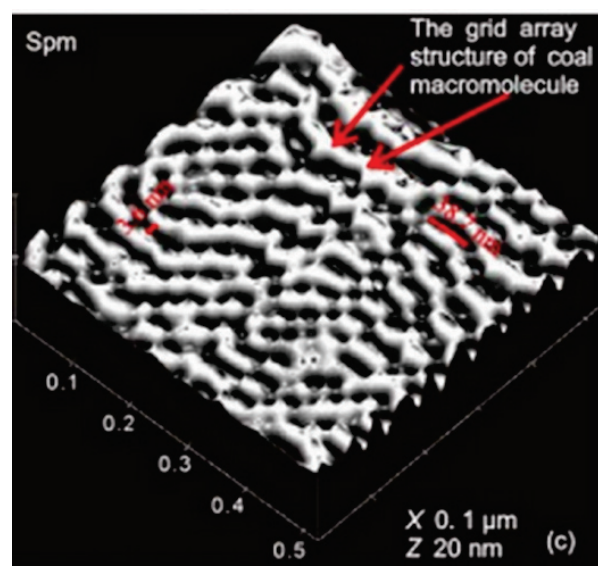

b

Fig. 1. Fragment with a size of $17 \times 17 \mathrm{~nm}$ HRTEM image of a monomolecular layer of bituminous coal (a) [4] and AFM section of the gas coal surface (b) [5].

The relationship between the components of biogeocenosis is conveniently presented in the form of a block scheme [6]. Here the structure of biogeocenosis is presented (Fig. 2) modified for mixed water-land or coastal ecosystems characteristic of Carbon. The edaphotope composition includes both bottom sediments and coastal soils, and phytocenosis includes higher vascular plants, hydrophytes, and phytoplankton.

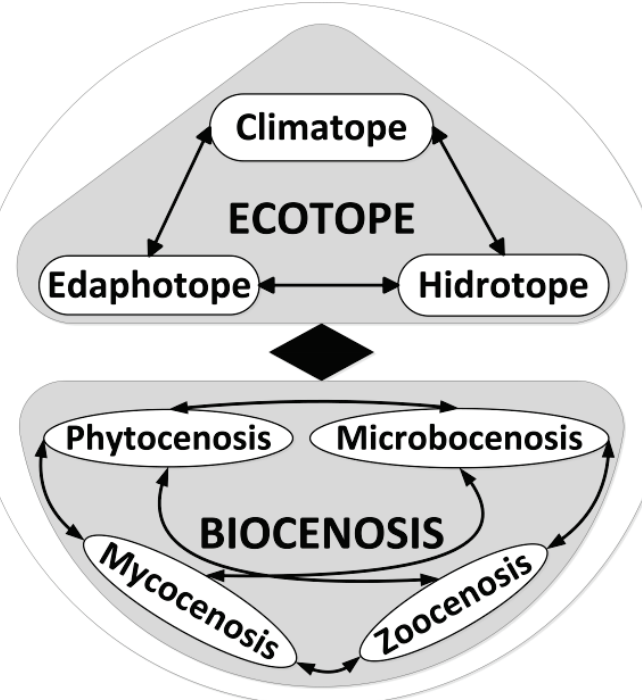

Fig. 2. The modified structure of biogeocenosis [6].

Phytocenosis is the main producer and basis of any ecosystem. It is known that in the Paleozoic era the land development by flora and fauna took place, and up to the 
Carboniferous period plants had formed real roots instead of rhizoids and rhizomes, the vascular system and the main photosynthetic organ - leaves. This allowed them to survive not only in wet places.

But coming ashore of higher plants does not mean the instant extinction of riniophytes and spore embryophytes. An example in the sustainability of ancient species is modern mosses. Aromorphoses only provided additional mechanisms for expanding the living conditions, and most evolved species initially developed amphibian landscapes.

The main abiotic regulator in biogeocenosis is climatope. As long as the climate was warm and humid, Devonian plants along with algae inhabited the hydrotope. At the end of Carbon - beginning of Perm, extreme climatic changes occurred. Cooling followed by an intense increase in temperature led to the death of adapted species and the realization of the competitive advantages of seed embryophytes.

As it is known, $\mathrm{O}_{2}$ is a by-product of plant photosynthesis. In the late Paleozoic, as a result of the plant biomes prosperity, the concentration of atmospheric oxygen was the highest in the entire history of the Earth. In Lower Perm, it could reach $30 \%$, and at $>25 \%$, fires would become widespread, especially in areas with a wetter climate, due to the abundance of lightning strikes. At the level more than $30 \%$, fires are spread worldwide. Accordingly, the most charcoal-like pyrolysis of wood is found in Perm coal intertinites [7].

In Carbon, vegetation has not yet captured all possible ecological niches on the Earth. $\mathrm{O}_{2}$ concentration was high up to $25 \%$, but not a critical one, therefore fires could not be global in nature. They selectively, but systematically regulated the number of populations. The biogenic methane emission by marshy biogeocenoses could contribute to local ignitions. Fires are a critical environmental factor in the carbon cycle. They return organic carbon to atmospheric $\mathrm{CO}_{2}$ by the shortest loop and enrich soils with ash and charcoal, contributing to the growth of a new generation of plants.

Over millions of years in the generally humid tropical climate of Carbon, short-term dry periods and decreasing the levels of ocean are inevitable, which lead to the death of plant communities and the accumulation of dry, highly flammable biomass. The evidence of periodic climate aridization is the presence of inclusions of amorphous silica precipitated by diatoms introduced by continental waters in the Donbas coals.

Frequent fires prevented the accumulation of large biomass on land and on the water surface as in modern peatlands. High temperatures could promote evaporation in the hydrotope, as well as the gelification of dissolved organic substance, suspended colloidal particles and semi-decomposed remains - the source material for the deposition of vitrinite of coals.

Evolution was occurring by increasing trophic levels in the ecological pyramid. A distinctive feature of the paleoecosystems of the period under consideration is the accumulation of the produced plant biomass due to the absence of large vertebrate phytophages, which appeared much later at the end of the Mesozoic with the spread of angiosperms. In the paleolithic bogs of Carbon, the primary consumers include insects and arthropods invertebrates, which obviously could not cope with the consumption of large biomass of autotrophs. Such conditions contributed to the accumulation of mortmass - the material of future coal beds.

In order to sustain the circuit of substance in such a biocenosis, the role of reducers is increasing: mycocenosis and microbocenosis. In the history of the Earth, there are examples of ecosystems without consumers. These are Precambrian algal-cyanobacterial mats from which ancient stromatolites were formed. In the Paleozoic hydrotopes, such multilayer microbial communities with different energy ways also existed.

Most of the biomass of terrestrial plants consists of natural polymers: lignin and cellulose. Lignin is completely mineralized to $\mathrm{CO}_{2}$ and $\mathrm{H}_{2} \mathrm{O}$ by the peroxide mechanism of saprophytic molds under aerobic conditions. Moreover, complete aerobic decomposition is 
possible by one type of reducers. This process contributes to the macerals deposition of the inertinite group in coals.

Having monopolized the niche of decomposition of lignocellulose, mycocenosis is central to the functioning of soil ecosystems and sedimentary deposits. In modern tropical mangrove forests, mineralization of plant litter by fungi and termites occurs very quickly. Therefore, the leaf mold does not have time to accumulate, and the soil is depleted in humus.

Saprophytic fungi are important reducers of organic substances in any aquatic ecosystem. Some of their varieties can decompose the stable structure of humic substances, using ligninolytic enzymes. This process leads to the complete or partial decomposition of organic compounds that are available for further mineralization by bacteria [8].

Anaerobic decomposition of cellulose is possible only by a combination of physiologically diverse microorganisms. The trophic structure of microbiocenosis is under the task of full energy usage of incoming organic substances due to thermodynamically advantageous chemical reactions. It is based on the cooperation of trophic links, the specialization of organisms upon the used substrates and the formed products.

The oligomeric product dispersed by hydrolytics-during polymer hydrolysis can be used by dissipotrophs. Both groups belong to primary anaerobic fermenters; they do not need an external electron flow and are responsible for the acidogenic phase. The most important products are $\mathrm{H}_{2}$, alcohols, acetate, and volatile fatty acids. Secondary anaerobes use all nonfermentable products of primary anaerobes as electron donors and external inorganic acceptors of electrons (nitrates, Mn (IV), Fe (III), sulfates) in redox reactions leading to the formation of $\mathrm{CO}_{2}$ and reduced inorganic compounds [9].

For an autonomous time-stable community it is necessary that the destruction must be complete, from the primary producers of autotrophs to complete decomposition without the accumulation of any intermediate waste products of the community. A high concentration of one of the intermediate substances in the community means the inefficiency of its consumption.

Microbiocenosis inhabiting the dead plants is vulnerable to relatively rapid change, their stabilization does not occur. They are characterized by a series of transitional stages of a decreasing energy gradient. Accumulation of the products of bacterial metabolism is essential in the evolution of such systems [10].

When oxygen is absent, anaerobic methanogenic and sulphidogenic competing communities decompose cellulose (Fig. 3). The most important node of the productsubstrate network is acetogenesis, which represents an intermediate stage between primary and secondary anaerobes. Since different organisms synthesize similar products, acetate accumulates in excess in the environment. Some types of bacteria secrete formiate, propionate, butyrate or valerate.

Another important network node is the accumulation of hydrogen. Very little hydrogen goes to the atmosphere, most acetogens, methanogens and sulphidogens can use $\mathrm{H}_{2}$ as an electron donor. Methanogens use $\mathrm{H}_{2}$ to restore $\mathrm{CO}_{2}$ to $\mathrm{CH}_{4}$, and homoacetogens use $\mathrm{CO}_{2}$ to restore to acetate. Hydrogentrophic methanogens act as the ultimate flow for $\mathrm{H}_{2}$, providing the ability to decompose of volatile fatty acids by syntrophs. Otherwise, hydrogen inhibits the process. If $\mathrm{H}_{2}$ is not used by hydrogentrophic methanogens, then a homoacetate shunt comes into effect.

Methanogenesis is the final phase in the reduction of organic substance. During the decomposition process, oxygen and inorganic electron acceptors are depleted, but $\mathrm{H}_{2}, \mathrm{CO}_{2}$, and low-molecular organic substances, forming at fermentation, accumulate. Only methanogenesis and primary fermentation can occur in the absence of electron acceptors, except carbon. Fermentation is aimed at the decomposition of only high-molecular organic compounds and the production of small organic substances. 


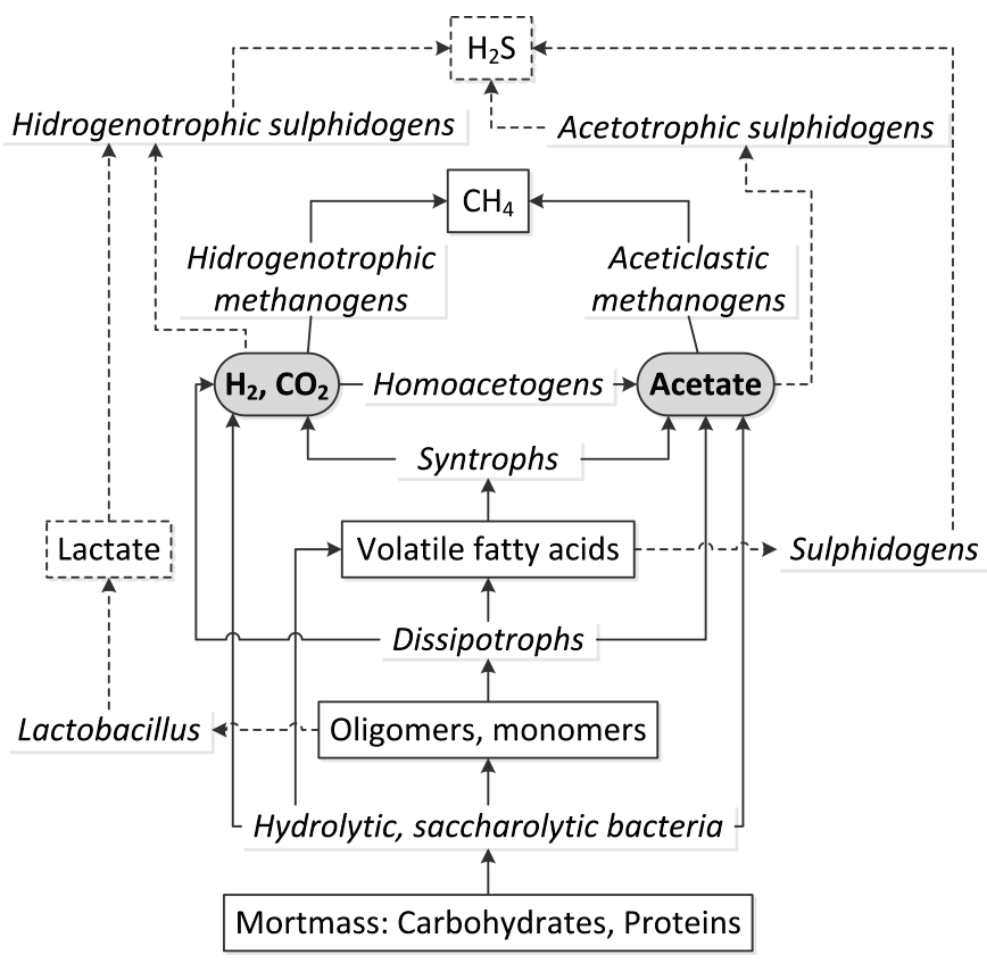

Fig. 3. Anaerobic decomposition scheme of cellulose by microbial communities [9].

An important ecological function of methanogenic archaea is the effective removal of fermentation products, which does not allow them to accumulate in anaerobic environments. Depending on $\mathrm{pH}$ and temperature, methanogens can use carbon from other small organic compounds: formic acid, methanol, methylamine, tetramethyl ammonium, dimethyl sulfide and methanethiol.

Sulfate reducers play a key role in carbon and sulfur cycles. They are extremely universal with respect to electron donors and acceptors and can grow on more than one hundred organic compounds, including monocarboxylic acids, dicarboxylic acids, sugars, alcohols, ketones, amino acids, aromatic compounds and hydrocarbons [11].

In modern sulfate-rich seawaters, there is usually a lack of organic substance, and external electron donors are required to complete recovery of sulfates. Although methanogens are more competitive in using organic electron donors, autotrophic sulfate reducers use hydrogen more efficiently.

Sulphidogens dwell in bottom sea sediments or are found in water bodies rich in decaying organic matter. Usually, they compete with methanogens growing in sediments of freshwater, for hydrogen, acetate and other substrates. Sulfate reducers usually dominate methanogens by suppressing them with hydrogen sulfide, since the sulfate reduction reaction is energetically more profitable. They can use a wider range of substrates.

In the community sulfate reducers primarily realize the flow of hydrogen. They prevent acidification of the environment using lactate formed by lactic acid bacteria.

For sulphidogenic communities, an important limiting factor is the influx of sulfate from the outside. Sulfate regeneration in the community is possible in two ways: the upper members of the community oxidize hydrogen sulfide aerobically or anoxigenic phototrophic bacteria - members of the community oxidize it anaerobically.

Besides a competition between methanogens and sulphidogens, there is a noncompetitive way for the metabolism of monocarbon compounds: for example, sulfate 
reducers can produce methanol, which they do not use further, but methanogens presented in the community can freely consume it.

The accumulation of hydrogen sulfide in water bodies due to eutrophication leads to a decrease in biodiversity. The anoxic-euxine stratification of the seas and oceans can be global in nature. This phenomenon is associated with mass extinctions of marine fauna in late Devon, Lower Perm and the end of the Triassic [12]. Hydrogen sulfide contributes to the deposition of nutrient pyrite. The process can be simplified by the reaction:

$$
\mathrm{Fe}^{2+}+2 \mathrm{HS}^{-} \rightarrow \mathrm{FeS}_{2}+2 \mathrm{H}^{+}
$$

In this way, sulfate reducers form fossile in the form of framboidal pyrite [13]

For experimental evidence concerning the presence of fatty acids and their salts in coal, DRIFT is suitable as a method sensitive to vibrations of heteronuclear links. On the presented infrared spectra of low-ash bituminous coals in Donbas of varying degrees of coalification (Fig. 4), one can see strong absorption bands, specific to the carboxyl groups of organic acids and the carboxylate anion during deprotonation, characteristic of biogenic deposits [14].

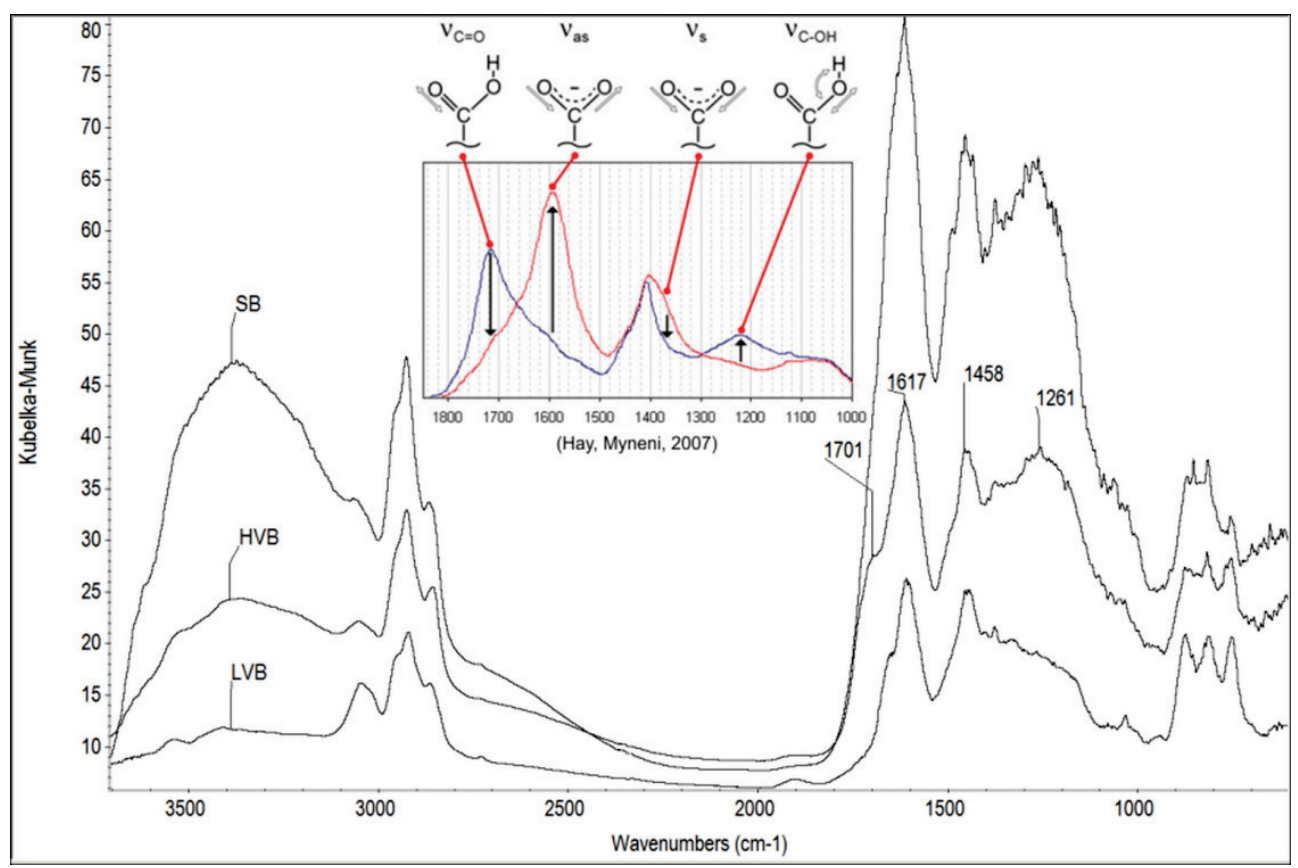

Fig. 4. DRIFT of typical low-ash bituminous coals in Donbas (SB - Sub-bituminous, HVB - High volatile bituminous and LVB - Low volatile bituminous).

A significant contribution to the molecular profile of coals is made by dissolved organic substances - the result of phytoplankton excretion and lysis of its cells. Among them, carbohydrates, nitrous compounds, organic acids, lipids, etc. predominate [15]. The first three groups are consumed by heterotrophic bacteria, the mineralization of which provides with nutrients to primary producers. Lipids and other molecules can accumulate in the environment, including such exotic ones as Dimethylsulfoniopropionate, Dimethysulfide, and Isoprene.

In a separate group of the molecular profile, one needs to distinguish stable in time organic compounds - lipids. The composition of wax lipids in most organisms vary and may include aliphatic hydrocarbons, primary and secondary alcohols, acids, ketones, 
aldehydes, esters, etc. Hydrocarbons are mainly represented by n-alkanes, but may include n-alkenes, branched saturated and unsaturated hydrocarbons, cyclic alkanes and isoprenoids. The wax of cuticle in higher plants can consist of $90 \%$ from hydrocarbons. It is resistant to atmospheric actions and microbial decomposition, forms coal leptynite. Amphiphilic lipids with polar and nonpolar groups play a key role in gelification of vitrinite.

The bactericidal activity of algae is associated with the release by them the free unsaturated fatty acids into the environment. Among them, long-chain linoleic and linolenic acids dominate. Unicellular green algae inhibit the growth of gram-positive bacteria (arrivals from land), especially bacilli, but do not affect gram-negative ones. Free fatty acids act on the cytoplasmic membrane of $\mathrm{Gram}^{+}$bacteria. Also, with the massive development of cyanobacteria and green algae, phenolic compounds accumulate, fission products of which can also act as growth inhibitors [16].

Sea fungi are potential producers of alkaloids derived from polyketides, terpenes, peptides, and compounds of mixed biosynthesis, which represent chemical groups of secondary metabolites. Thousands of compounds of mycotoxins, antibiotics, vitamins, stimulants and growth inhibitors and other biologically active substances were extracted from fungi.

And finally, it is worth mentioning the environmental role of viruses that selectively infect bacteria and archaea. Bacteriophages multiply inside bacterial cells and cause their lysis. Under natural conditions, phages are found where there are bacteria sensitive to them. Bacteriophages control the number of microbial populations by autolysis of aging cells, introduce new genes into the bacterial genome by transduction. Viruses are an important regulator of microbocenosis, at least half of the bacteria in aquatic ecosystems die of them. Due to lysis, the phages saturate the hydrotope with the protoplasm substance of prokaryotes and the material of their cell membrane.

Microorganisms in the coal formation ecosystem play a key role. Bacteria, archaea, yeast, protozoa, and viruses participate in the circulation of matter and energy, secrete or contribute to the release of a large volume of various waste products. Their decomposition of high-molecular plant compounds is so effective that low-molecular metabolites form the basis of the molecular profile of coals. The polymers presented in coal are largely the result of the secondary biosynthesis of reducers.

The activity of the microbiota does not stop even after submerging the coal bed in the geological stratum. The process of methanogenesis continues in our time [17]. Methane, associated with coal beds, can be not only thermogenic but also biogenic in nature. Accumulations of methane of microbial origin were found in many coal beds by the characteristic ratios of carbon isotopes $\mathrm{CH}_{4}$ and $\mathrm{CO}_{2}$. More biogenic methane is in lowmaturity coals [18].

A long-term change in the microbial community in biostimulated coal bed water led to increasing methanogenesis. Methanogenic archaea are the main part of biofilms communities, connected with coal, that carries out acetoclastic methanogenesis in an initially gas-free coal bed. In coal beds, even in sulfate-rich waters, methanogens win a competition with sulphidogens in the struggle for the main resource - acetate [19].

Recent studies have shown strong variability in the volumes of biogenic methane produced in coal. The forecast depends on nutrients accumulated during sedimentation, their availability to methanogens, and favorable ecotope conditions in the coal bed. The functioning of the microbocenosis of a specific coal bed ecosystem can be considered as a high internal factor in coalification and molecular profile variability [20].

In conclusion, it is worth noting that application of the concept of the molecular profile of coals based on the ecosystem approach will allow to solve both the direct problem in restoring the biogeochemical situation during sedimentation period by the presence of 
characteristic organic compounds in coals and the inverse task of forecasting the composition of the molecular profile from known geological data. In addition, there are prospects for increasing the production of biogenic methane in those coal beds whose ecological history allows this to be done.

\section{Conclusions}

Deposits of fossil coals in significant volumes can be formed in the evolution process of the Earth's biosphere, and they are the result of biogeocenosis functioning. The emergence of specific biomes with short trophic chains, an imbalance in the carbon cycle and desynchronization in the flows of substance and energy are due to a unique combination of ecological factors.

In contrast to popular belief, the molecular structure of coal is a complex conglomerate of various stable organic compounds. It mainly consists of primary and secondary metabolites of biogeocenosis reducers and their cellular substance. The molecular profile of coals includes numerous classes of low- and high-molecular organic substances that interact closely with each other. Multiple classes are not endless, the interaction is not chaotic, and their number and relationships are determined by paleoecologic patterns and coalification.

Combinations of various compounds determine many of the physicochemical properties of coals. Due to the metastable, multiphase and multicomponent nature of the coal substance, complete decoding of the molecular profile is difficult. Even a small fragment of the profile includes valuable information about the genesis of individual compounds and the paleoecological situation in the sedimentation period when forming the coal beds of individual deposits.

Microbiota impact does not end with a period of mortmass accumulation, which is never fully mineralized. After burial by sedimentary rocks and swamp dehydration, the active life of microorganisms is suspended. However, in the future favorable environmental conditions may develop for the rebirth of the microorganisms' activity in coal beds, including nowadays.

\section{References}

1. Van Krevelen, D.W. (1993). Coal: Typology-Physics-Chemistry-Constitution. Amsterdam: Elsevier Science

2. Mathews, J.P., Chaffee, A.L. (2012). The molecular representations of coal - A review. Fuel, 96 (1), 1-14

3. Ke-Chang, Xie. (2015). Structure and reactivity of coal: A survey of selected Chinese coals. Springer-Verlag. Berlin, Heidelberg

4. Sharma, A., Kyotani, T., Tomita, A. (1999). A new quantitative approach for microstructural analysis of coal char using HRTEM images. Fuel, 78 (10), 1203-1212

5. Suping, Yao, Kun, Jiao, Ke, Zhang, WenXuan, Hu, Hai, Ding, MiaoChun, Li, WenMing, Pei. (2011). An atomic force microscopy study of coal nanopore structure. Chinese Science Bulletin, 56 (25), 2706-2712

6. Sukachev, V.N., Lavrenko, Y.M. (1972). Izbrannye trudy v trekh tomakh. Tom 1: Osnovy lesnoy tipologii i biogeotsenologii. Leningrad: Nauka

7. Scott, A.C., Glasspool, I.J. (2006). The diversification of Paleozoic fire systems and fluctuations in atmospheric oxygen concentration. Proceedings of the National Academy of Sciences of the United States of America, 103 (29), 10861-10865

8. Grossart, H.-P., Keilor, R.J. (2016). Aquatic fungi: Targeting the forgotten in microbial ecology. Current Opinion in Microbiology, 31, 140-145 
9. Zavarzin, G.A., Kolotilova, N.N. (2003). Lektsii po prirodovedcheskoy mikrobiologii. Moscow: Nauka

10. Gromov, B.V., Pavlenko, G. V. (1989). Ekologiya bakterii. Leningrad: Izdatelsvo LGU

11. Barton, L.L., Fauque, G.D. (2009). Biochemistry, physiology and biotechnology of sulfate-reducing bacteria. Advances in Applied Microbiology, 68, 41-98

12. Schobben, M., Stebbins, A., Ghaderi, A,, Strauss, H., Korn, D., Korte, C. (2015). Eutrophication, microbial-sulfate reduction and mass extinctions. Commun Integr Biol., 9 (1): e1115162

13. Popa, R., Kinkle, B.K., Badescu, A. (2004). Pyrite Framboids as Biomarkers for IronSulfur Systems. Geomicrobiology, 21 (3), 193-206

14. Hay, M.B., Myneni, S.C.B. (2007). Structural environments of carboxyl groups in natural organic molecules from terrestrial systems. Part 1: Infrared spectroscopy. Geochimica et Cosmochimica Acta, 71 (14), 3518-3532

15. Thornton, D.C.O. (2014). Dissolved organic matter (DOM) release by phytoplankton in the contemporary and future ocean. European Journal of Phycology, 49 (1), 20-46

16. Dobrovolskaya, T.G. (2002). Struktura bakterialnykh soobshchestv pochv. Moscow: IKTs Akademkniga

17. Meslé, M.; Dromart, G.; Oger, P. (2013) Microbial methanogenesis in subsurface oil and coal. Res. Microbiol., 164, 959-972

18. Strapoc, D., Mastalerz, M., Dawson, K., Macalady, J., Callaghan, A.V., Wawrik, B., Turich, C., Ashby, M. (2011). Biogeochemistry of microbial coal-bed methane. Annual Review of Earth and Planetary Sciences, 39, 617-656

19. Beckmann, S., Luk, A.W.S., Gutierrez-Zamora, M.-L., Chong, N.H.H., Thomas, T., Lee, M., Manefield, M. (2019). Long-term succession in a coal seam microbiome during in situ biostimulation of coalbed-methane generation. The ISME Journal, 13, 632-650

20. L. Pymonenko, O. Burchak, O. Balalaiev, V. Slobodiannykova, Yu. Sierikov. Change of parameters in molecular structure of Donbas coals under the influence of external factors. E3S Web of Conferences, International Conference Essays of Mining Science and Practice, 109 (2019). https://doi.org/10.1051/e3sconf/201910900077 